\title{
Some mechanical properties of aggregates of top soils from the IJsselmeer polders. 2. Remoulded soil aggregates and the effects of wetting and drying cycles
}

\author{
A. R. Dexter ${ }^{1}$, B. Kroesbergen² and H. Kuipers ${ }^{2}$ \\ Waite Agricultural Research Institute, University of Adelaide, Glen Osmond, \\ South Australia 5064, Australia \\ 2 Tillage Laboratory, Agricultural University, Diedenweg 20,6703 GW Wage- \\ ningen, Netherlands
}

Accepted: 19 June 1984

Key-words: age-hardening, aggregates, Atterberg Limits, friability, mellowing, porosity, slaking, tensile strength, wetting and drying

\section{Summary}

The mechanical properties of remoulded samples of eight soils from the IJsselmeer polders were investigated. The Atterberg (Plastic and Liquid) Limits are found to be positively correlated with soil clay content, but not significantly correlated with organic matter content. Artificial aggregates of the remoulded soil are found to age-harden when moist.

Tensile strength of artificial aggregates is found to be positively correlated with soil clay content and negatively correlated with porosity. Friability of the dried, remoulded soil is much lower than that of natural, undisturbed soil.

Factors affecting the rates of wetting and drying of aggregates in the laboratory are examined in detail. Wetting is shown to result in mellowing (or softening) of artificial aggregates. Mellowing is investigated as a function of the potential of the source of water causing the wetting. It is shown that multiple wetting and drying cycles may result in increased mellowing or in no mellowing depending on the water potential. New terminology is introduced to facilitate discussion of these phenomena.

\section{Introduction}

On arable land, soil is continually being moulded by the actions of tractor wheels and tillage implements (Koolen \& Kuipers, 1983). This moulding can take the forms of compaction or shearing and sometimes smearing. If the operations of mechanized agriculture are done when the soil is too wet, or in combination with a bad system of farm management, then the soil can loose much of its aggregate struc- 
ture through these moulding processes. The soil can then be difficult to work and can have physical properties which are not adequate for crop growth (Bouma, 1969; Kuipers, 1982).

It is often observed that the action of the weather can reverse the adverse effects of this moulding. The intermittent wetting and drying of the surface soil through the action of the weather can result in the break-down of compacted clods and of smeared surfaces. This is the phenomenon of 'tilth mellowing' (Utomo \& Dexter, 1981a).

In Part I of this study (Dexter, Kroesbergen \& Kuipers, 1984), some mechanical properties of undisturbed aggregates of top soils from the IJsselmeer polders were reported. In Part II, some properties of remoulded aggregates of the same eight soils are presented. In addition, we examine some effects of wetting and drying cycles on remoulded soil aggregates. This gives us basic information on some of the factors involved in the tilth mellowing process.

\section{Materials and methods}

\section{Soils}

The soils have been described fully in Part I (Dexter, Kroesbergen \& Kuipers, 1984). However, for completeness, some of the more important properties are summarized in Table 1. In addition, Table 1 includes values of the Plastic Limit, PL, and Liquid Limit, LL, of the soils. The values of the Plastic Limit are well described by

$$
\begin{gathered}
\mathrm{PL}=20.5+0.30 \mathrm{C}, \% \\
( \pm 1.1)( \pm 0.04)
\end{gathered}
$$

which accounts for $89.7 \%$ of the variance. $\mathrm{C}$ is the clay content (\%). In Eq. 1, and in all following equations, the figues in brackets $( \pm)$ are the standard errors of the mean fitted parameters.

The Liquid Limits, LL, can be described by

Tabie 1. Details of the experimental soils. Sampling location, clay and organic matter contents, and Plastic and Liquid Limits (PL and LL).

\begin{tabular}{lllllll}
\hline Soil & $\begin{array}{l}\text { Sampling location } \\
\text { (land parcel) }\end{array}$ & $\begin{array}{l}\text { Age } \\
\text { (yrs) }\end{array}$ & $\begin{array}{l}\text { Clay, \% } \\
(<2 \mu \mathrm{m})\end{array}$ & $\begin{array}{l}\text { Organic matter } \\
(\%)\end{array}$ & $\begin{array}{l}\text { PL } \\
(\%)\end{array}$ & $\begin{array}{l}\text { LL } \\
(\%)\end{array}$ \\
1 & $\mathrm{M}_{70}$ & 42 & 26.6 & 3.2 & 27.6 & 39.7 \\
2 & $\mathrm{P}_{42}$ & 42 & 14.4 & 2.4 & 23.1 & 28.7 \\
3 & $\mathrm{H}_{91}$ & 25 & 18.9 & 3.1 & 26.2 & 33.9 \\
4 & $\mathrm{~K}_{21}$ & 25 & 25.2 & 3.3 & 29.2 & 40.6 \\
5 & $\mathrm{U}_{16}$ & 25 & 40.8 & 4.4 & 32.6 & 51.3 \\
6 & $\mathrm{Qz}_{52}$ & 14 & 39.6 & 3.3 & 31.9 & 49.0 \\
7 & $\mathrm{~N}_{770}$ & 14 & 42.8 & 4.4 & 33.9 & 53.6 \\
8 & $\mathrm{Nz}_{47}$ & 14 & 15.1 & 2.9 & 26.7 & 28.6 \\
\hline
\end{tabular}




$$
\begin{gathered}
\mathrm{LL}= \\
( \pm 1.3)+0.84 \mathrm{C}, \% \\
( \pm 0.04)
\end{gathered}
$$

which accounts for $98.3 \%$ of the variance. Any effects of organic matter on PL or LL were not statistically significant.

\section{Experimental methods}

Soil samples were oven-dried, allowed to cool in a desiccator over silica gel, and then weighed. Weighed amounts of water were then added and thoroughly mixed with the soil. The water contents used were usually exact proportions (e.g. 1.00, $1.05, \ldots, 1.25)$ of the Plastic Limits of the soils.

Artificial aggregates were then made by moulding the soil in the hands and rolling it into balls. These balls were left to air-dry in the laboratory, and were then oven-dried at $105^{\circ} \mathrm{C}$ for 24 hours. Before testing, the aggregates were cooled in a desiccator over silica gel.

Porosities of the dry aggregates were measured by the method of McIntyre \& Stirk (1954). The standard errors of the mean porosity values obtained are estimated to be $0.002(\mathrm{v} / \mathrm{v})$. Like in part I, tensile strength values were calculated from measurements of the forces required to crush the aggregates between flat, parallel plates (method 2.4 of Dexter \& Kroesbergen, in press), and were calculated by method 2 of Dexter and Kroesbergen (in press). Sample size in the crushing tests was typically 10 . The direction of crushing was always in the direction of wetting to eliminate any effects of anisotropy (Dexter, 1983).

For the experiments on the effects of wetting and drying cycles, wetting was done by placing the dry aggregates on a suction table. The suction table comprised a bed of saturated, fine sand connected to a water reservoir with a free water surface at an adjustable height, $h$, below the surface of the sand. Drying was done by placing the aggregates on the laboratory bench for 24 hours, after which they were dried at $105{ }^{\circ} \mathrm{C}$ for a further 24 hours. Rates of wetting and drying were determined, using separate batches of aggregates, by periodic weighings of individual aggregates to determine the net gains or losses of water as functions of time. It was assumed that the matric water potential, $\psi=h$.

\section{Results and discussion}

\section{Age-hardening}

Aggregates of Soil 4 were made by moulding at a water content of $1.2 \mathrm{PL}$ as described above. Three sub-samples of these aggregates were examined. One subsample was dried immediately and crushed; the second sub-sample was stored on the suction table at a water potential of $\psi=100 \mathrm{~cm}$ for 4 days and was then dried and crushed; the third sub-sample was stored at $\psi=100 \mathrm{~cm}$ for 27 days and was then dried and crushed. The tensile strength values of these sub-samples were $325 \pm 14,384 \pm 16$ and $1025 \pm 48 \mathrm{kPa}$, respectively. This indicates that age-hardening occurred in these aggregates at $\psi=100 \mathrm{~cm}$ at an approximate rate of increase of $8 \%$ of the original value per day. However, there is no reason to expect a linear in- 
crease of strength with time (Utomo \& Dexter, 1981b).

In order to minimize any confounding effects from age-hardening, aggregates were always dried immediately after moulding or immediately after wetting unless it is stated otherwise.

\section{Comparison of the different soils}

Batches of artificial aggregates of the eight soils were made by moulding at 1.25 PL, and the porosities and tensile strengths of the dry aggregates were measured as described above. The results are given in Table 2 . The average pore space of the three light soils $(2,3,8)$ is only slightly higher than of the three heavy soils $(5,6,7)$. The average of the two medium textured soils is slightly lower. In each group pore space of the younger soils is higher than of the older soils. The tensile strength values, $Y$, can be described by

$$
\begin{gathered}
Y=1785+3.9 \mathrm{C}-4071 \eta, \mathrm{kPa} \\
( \pm 373)( \pm 1.6)( \pm 1909)
\end{gathered}
$$

where $\mathrm{C}$ is the clay content $(\%)$ and $\eta$ is the porosity $(\mathrm{v} / \mathrm{v})$. Eq. 3 accounts for $78.9 \%$ of the variance.

Table 2. Properties of dry, artificial aggregates prepared by moulding the soils at water contents of 1.25 $\mathrm{PL}$, where PL is the soil Plastic Limit.

\begin{tabular}{lll}
\hline Soil & $\begin{array}{l}\text { Porosity, } \eta \\
(\mathrm{v} / \mathrm{v})\end{array}$ & $\begin{array}{l}\text { Tensile strength, } Y \\
(\mathrm{kPa})\end{array}$ \\
1 & 0.373 & $378 \pm 31$ \\
2 & 0.389 & $203 \pm 10$ \\
3 & 0.400 & $258 \pm 13$ \\
4 & 0.406 & $243 \pm 16$ \\
5 & 0.395 & $400 \pm 15$ \\
6 & 0.397 & $336 \pm 16$ \\
7 & 0.421 & $173 \pm 11$ \\
8 & 0.443 & $72 \pm 4$ \\
\hline
\end{tabular}

Table 3. Porosity and tensile strength values of dry aggregates of Soil 4 which had been prepared by moulding at different water contents. Water contents at moulding are expressed in terms of the Plastic Limit, PL, of the soil.

\begin{tabular}{lll}
\hline $\begin{array}{l}\text { Moulding water content, } w_{\mathrm{m}} \\
(\%)\end{array}$ & $\begin{array}{l}\text { Porosity, } \eta \\
(\mathrm{v} / \mathrm{v})\end{array}$ & $\begin{array}{l}\text { Tensile strength, } Y \\
(\mathrm{kPa})\end{array}$ \\
$1.00 \mathrm{PL}$ & 0.366 & $543 \pm 30$ \\
$1.05 \mathrm{PL}$ & 0.357 & $607 \pm 38$ \\
$1.10 \mathrm{PL}$ & 0.375 & $513 \pm 28$ \\
$1.15 \mathrm{PL}$ & 0.377 & $472 \pm 27$ \\
$1.20 \mathrm{PL}$ & 0.380 & $436 \pm 27$ \\
$1.25 \mathrm{PL}$ & 0.400 & $299 \pm 8$ \\
\hline
\end{tabular}


If the clay content term is omitted, we get

$$
\begin{gathered}
Y=1975-4265 \eta, \mathrm{kPa} \\
( \pm 494)( \pm 1224)
\end{gathered}
$$

which accounts for only $61.4 \%$ of the variance. However, we shall use Eq. 4 later for the purposes of making simple comparisons.

Effect of different moulding water contents

Samples of Soil 4 were moulded at different gravimetric water contents, $w_{\mathrm{m}}(\%)$, into artificial aggregates. The porosities and tensile strengths of dried batches of these aggregates were measured as described above. The results are given in Table 3 . Higher moulding water content values gave a larger porosity in the dried aggregates. The following relation describes this

$$
\begin{gathered}
\eta=0.22+0.0047 w_{m} \\
( \pm 0.04) \quad( \pm 0.0013)
\end{gathered}
$$

which accounts for $72.1 \%$ of the variance.

In Table 3, it can be seen that porosity apparently goes through a minimum and tensile strength apparently goes through a maximum at $w_{\mathrm{m}}=1.05 \mathrm{PL}$. In spite of this, a good linear relationship exists between tensile strength, $Y$, and porosity:

$$
\begin{gathered}
Y=3188-7210 \eta, \mathrm{kPa} \\
( \pm 191)( \pm 509)
\end{gathered}
$$

which accounts for $97.6 \%$ of the variance.

\section{Friabilities}

Aggregates of Soil 4 were prepared by moulding at $w_{\mathrm{m}}=1.2 \mathrm{PL}$ into two narrow size ranges having mean diameters of $5.5 \mathrm{~mm}$ and $12.0 \mathrm{~mm}$. The mean tensile strength of the larger aggregates was 0.76 of that of the smaller aggregates. This corresponds to a value of friability, as determined by the method of Utomo \& Dexter (1981c), of $k=0.12$, which is a low value.

A sample of Soil 4 was puddled thoroughly mixing it with water at gravimetric water content of approximately $w_{\mathrm{m}}=54 \%$ (or $1.85 \mathrm{PL}$ ). After air-drying, the puddled soil was broken up into aggregates and sieved into the 3.4-4.0, 4.8-6.8 and $8.0-9.6 \mathrm{~mm}$ size ranges. The porosity of the dried, puddled soil was $\eta=0.41(\mathrm{v} / \mathrm{v})$. For the aggregates from the puddled soil, tensile strength was independent of aggregate size to within experimental error. This corresponds to a value of friability of $k=0.0$.

\section{Wetting and drying rates}

The wetting rate results were normalized so that they fell into the range $0-1$ by transforming the gravimetric water content, $w_{1}$, at any time $t$ (s) onto a scale 
$\left(w_{\mathrm{t}}-w_{\mathrm{i}}\right) /\left(w_{\mathrm{f}}-w_{\mathrm{i}}\right)$. Similarly, the water contents in the experiments on drying rates were transformed onto a scale $\left.\left(w_{\mathrm{t}}-w_{\mathrm{f}}\right) / w_{\mathrm{i}}-w_{\mathrm{f}}\right)$, where $w_{\mathrm{i}}$ and $w_{\mathrm{f}}$ are the initial and final water contents, respectively. Typical wetting and drying curves are shown in Fig. 1 and 2 . The times, $t_{1 / 2}$, for one-half of the water content changes to occur were recorded.

The effect of soil texture on wetting rate was investigated by comparing the values of $t_{1 / 2}$ obtained for Soils 1,4 and 6 . The values were 9600,7330 and $29440 \mathrm{~s}$, respectively. For the heavier soil (6) it obviously took more time to reach equilibrium. Wetting speed may be rather low in this case because age-hardening of the aggregates took place for a period of 4 weeks at a water potential of $\psi=100 \mathrm{~cm}$.

The effect of soil porosity on wetting rate was investigated by comparing the values of $t_{1 / 2}$ obtained with aggregates of Soil 4 which had been moulded at different water contents as shown in Table 3 . The results can be expressed as

$$
\begin{gathered}
\log _{\mathrm{e}} t_{1 / 2}=7.43\left(-0.49-1.52 \log _{\mathrm{e}} \eta\right), \\
( \pm 0.32)( \pm 0.33)
\end{gathered}
$$

where $\eta$ is the porosity (v/v). Eq. 7 accounts for $83.8 \%$ of the variance. The factor in brackets is chosen to be equal to unity for $\eta=0.375$.

The effect of matric potential of the source of water on the wetting rate was investigated by comparing the values of $t_{1 / 2}$ obtained by wetting aggregates of Soil 4 from the oven-dried condition to matric water potentials of $\psi=5,10,20$ and $100 \mathrm{~cm}$. This gave values of $t_{1 / 2}$ of $1830,1810,1980$, and $7330 \mathrm{~s}$, respectively. Similar experiments with aggregates of Soil 6 wetted to matric water potentials of $\psi=5,10$ and

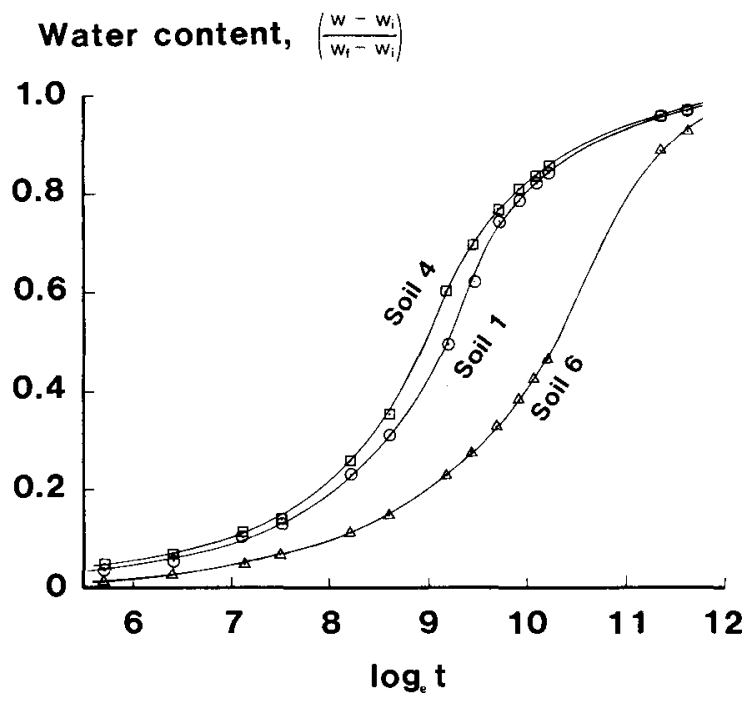

Fig. 1. Wetting curves for remoulded aggregates of Soils 1,4 and 6 . The aggregates of about $1 \mathrm{~g}$ weight were wetted to a potential of $100 \mathrm{~cm}$ from the oven-dry condition. 


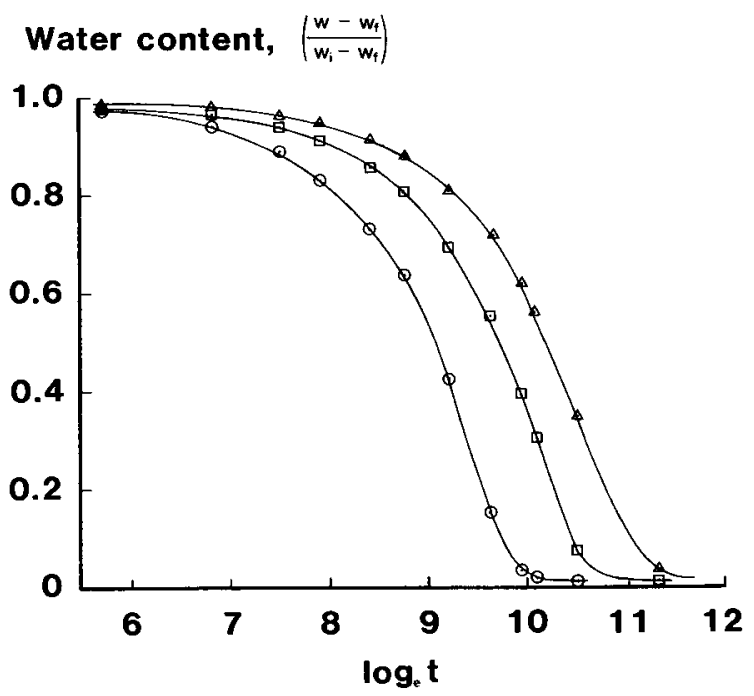

Fig. 2. Drying curves for remoulded aggregates of Soil 1. Aggregates of $0.666 \mathrm{~g}(o), 2.180 \mathrm{~g}(\square)$, and $6.867 \mathrm{~g}(\Delta)$ were air-dried from a potential of $100 \mathrm{~cm}$ in the laboratory.

$100 \mathrm{~cm}$, gave corresponding values of $t_{1 / 2}$ of 1410,2840 and $29400 \mathrm{~s}$.

The effect of aggregate size was investigated by comparing the values of $t_{1 / 2}$ obtained by wetting aggregates of Soil 4 of different mass, $m(\mathrm{~g})$. Aggregates of mass $0.115,0.165,1.533$ and $1.887 \mathrm{~g}$ were wetted from oven-dry to $\psi=100 \mathrm{~cm}$. This gave values of $t_{1 / 2}$ of $57000,57000,73100$ and $125500 \mathrm{~s}$ respectively.

As a first approximation, it is possible to ignore interactions, and to combine all results in a general equation for wetting of oven-dry, remoulded aggregates:

$$
\begin{aligned}
\log _{\mathrm{e}} t_{1 / 2}=7.5 & \left(-0.073+0.333 \log _{\mathrm{c}} \mathrm{C}\right) \\
& \left(-0.49+1.52 \log _{\mathrm{c}} \eta\right) \\
& \left(0.73+0.091 \log _{\mathrm{c}} \psi\right) \\
& \left(1+0.019 \log _{\mathrm{c}} m\right)
\end{aligned}
$$

Eq. 8 accounts for the observed behaviour to within experimental error, the factors in brackets are equal to unity for the following standard conditions: clay content, $\mathrm{C}$ $=25.2 \%$; porosity, $\eta=0.375$; wetting from a matric potential of $\psi=20 \mathrm{~cm}$, and aggregate mass, $m=1 \mathrm{~g}$.

Aggregate drying rates seemed to be relatively insensitive to soil type and were found to be dependant mainly on the total mass of water, $m_{\mathrm{i}}$, initially present $\left(m_{\mathrm{i}}=\right.$ $w_{\mathrm{i}} m$, where $w_{\mathrm{i}}$ is the initial gravimetric water content, expressed as a proportion, and $m(\mathrm{~g})$ is the dry mass of the aggregate), and aggregate size (here measured by $m$ ). The time, $t_{1 / 2}$, for one-half of the water loss to occur was given by

$$
\begin{aligned}
\log _{\mathrm{e}} t_{1 / 2}= & \left(10.4+\log _{\mathrm{e}}\left(w_{\mathrm{i}} m\right)\right)\left(1+0.057 \log _{\mathrm{e}} m\right) \\
( \pm 0.1) & ( \pm 0.004)
\end{aligned}
$$


Effects of superimposed wind speeds of $0-0.09 \mathrm{~m} \mathrm{~s}^{-1}$ had no significant effect on drying rate. Air temperature in the laboratory (around $20^{\circ} \mathrm{C}$ ) would have been important, but effects of this were not investigated.

\section{Aggregate mellowing}

When oven-dried aggregates were wetted to various water potentials on the tension tables, and then re-dried and crushed, it was found that they had mellowed (or softened). The aggregates were weaker (had smaller values of tensile strength) than control aggregates which had not been wetted. This effect was measured by the mellowing ratio which is defined as the ratio of the tensile strength of test aggregates to the tensile strength of control aggregates. It was demonstrated that the mellowing was more likely caused by the wetting rather than the drying phase by using two different drying rates. Sub-samples of a batch of aggregates were air-dried and oven-dried respectively, to obtain different drying rates, and no significant difference in tensile strength between the batches was observed.

Experimental values of the mellowing ratio, $R$, for Soils 4 and 6 are plotted in Fig. 3. It can be seen that for both soils within the region examined, $R$ increases almost linearly with increasing matric potential, $\psi$, of the source of water. For Soil 4 , this is given by

$$
\begin{gathered}
R=0.095 \\
( \pm 0.023) \quad( \pm 0.001)
\end{gathered}
$$

and for Soil 6 by

\section{Mellowing ratio, $\mathbf{R}$}

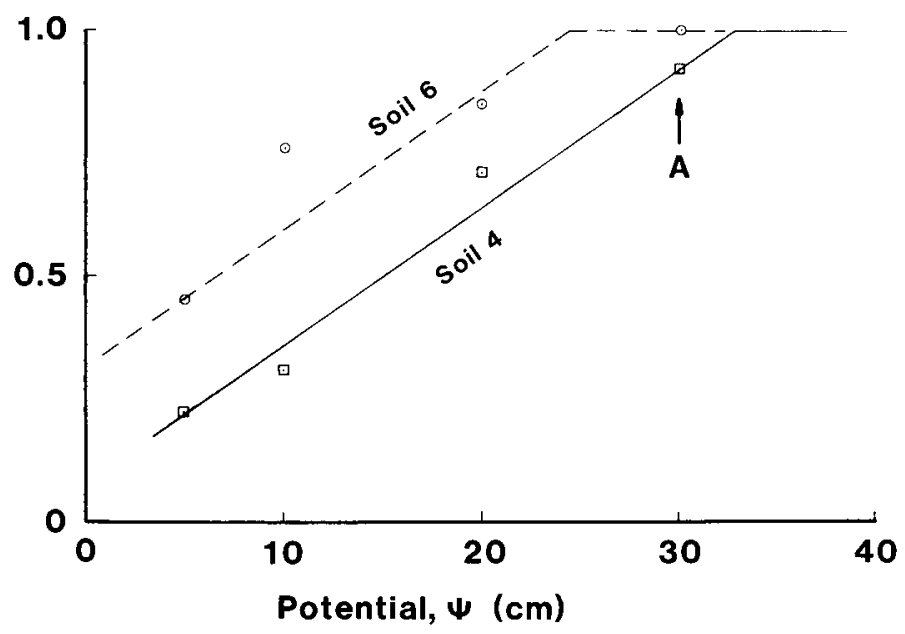

Fig. 3. Mellowing ratios, $R$, for remoulded aggregates of Soils 4 and 6 which had been re-wetted to the potential, $\psi$. 


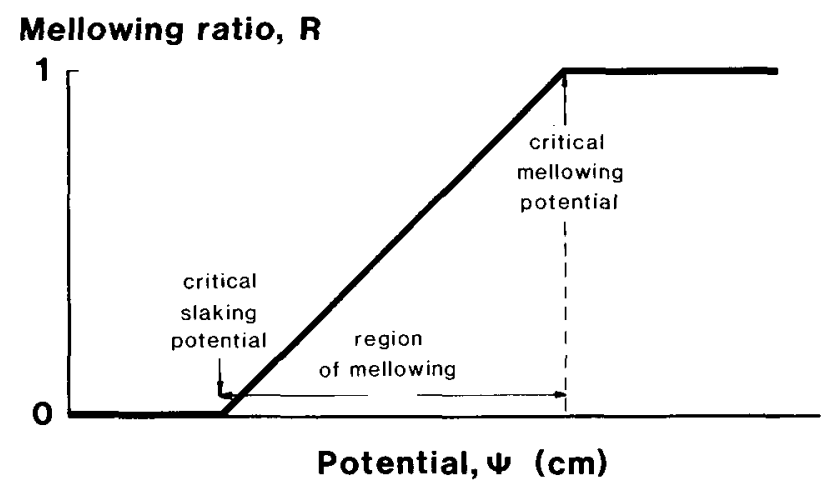

Fig. 4. Definitions of three terms which are used in the text.

$$
\begin{aligned}
R= & 0.405+0.024 \psi \\
( \pm 0.173) & ( \pm 0.013)
\end{aligned}
$$

Eq. 10 and 11 account for $99.5 \%$ and $54.5 \%$ of the variance, respectively.

For values of $\psi$ larger than some critical value, $\psi_{\mathrm{m}}$, wetting causes no mellowing and $R=1$ by definition. The value of $\psi_{\mathrm{m}}$ is different for different soils. From Eq. 10 and 11 , it can be predicted that $\psi_{\mathrm{m}}=30.8 \mathrm{~cm}$ for Soil 4 and $\psi_{\mathrm{m}}=24.7 \mathrm{~cm}$ for Soil 6 . We call $\psi_{\mathrm{m}}$ the critical mellowing potential of the soil aggregates. At the other end of the scale, $R$ tends towards zero. When $R=0$, the aggregate tensile strength becomes zero, and the aggregates would fall apart on wetting or slake. The largest value of $\psi$ where $R=0$ is called the critical slaking potential of the soil aggregates. The region where $0<\mathrm{R}<1$ we call the region of mellowing or the region of partial slaking. These regions and critical potentials are illustrated in Fig. 4.

It is likely that $R$ in the experiment discussed was most dependent on the matric potential, $\psi$, of the source of the water causing aggregate wetting. $\psi$ has a strong effect on the steepness of the wetting fronts passing through the aggregates.

\section{Multiple wetting and drying cycles}

Large batches of artificial aggregates of Soils 1,4 and 6 were prepared for a study of the effects of multiple wetting and drying cycles. Wetting was to a matric water potential of $\psi=30 \mathrm{~cm}$ for $24 \mathrm{~h}$ and drying consisted of air-drying for $24 \mathrm{~h}$ followed by oven-drying. After each cycle, sub-samples of the aggregates were crushed to determine their tensile strengths. The results of the medium-textured Soils 1 and 4 are shown in Fig. 5. It can be seen that there was a progressive reduction in tensile strength with increasing numbers, $N$, of wetting and drying cycles. The heavier Soil 6 showed no significant change in aggregate strength on wetting and drying. For Soil 1,

$$
\begin{gathered}
Y=971-42.5 N, \mathrm{kPa} \\
( \pm 12) \quad( \pm 5.1)
\end{gathered}
$$




\section{Tensile strength $(\mathrm{kPa})$}

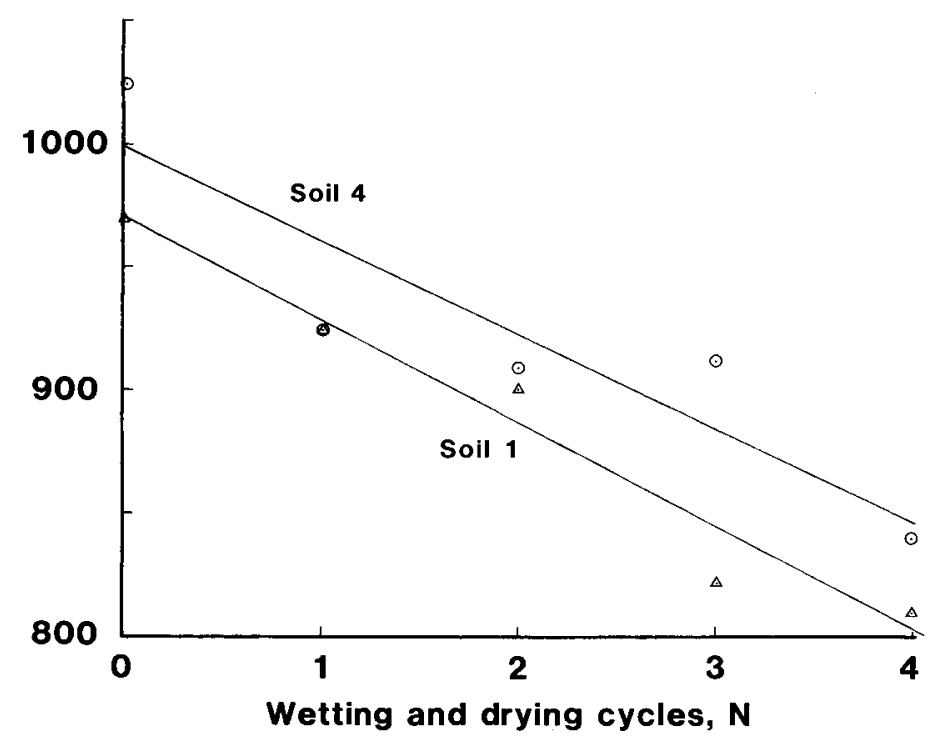

Fig. 5. Reductions in tensile strengths of remoulded aggregates of Soils 1 and 4 with increasing numbers of wetting and drying cycles. Aggregates were wetted at $30 \mathrm{~cm}$ potential which is shown by the point $\mathrm{A}$ in Fig. 3.

and for Soil 4

$$
\begin{gathered}
Y=998-38.0 N, \mathrm{kPa} \\
( \pm 25) \quad( \pm 10.2)
\end{gathered}
$$

which account for $94.5 \%$ and $76.3 \%$ of the variance respectively.

The slopes $(\mathrm{d} Y / \mathrm{d} N)$ of the lines in Eq. 12 and 13 are related to the mellowing ratios, $R$, by

$$
R=1+-\frac{1}{Y_{\mathrm{o}}}\left(\frac{\mathrm{d} Y}{\mathrm{~d} N}\right)
$$

where $Y_{0}$ is the value of $Y$ at $N=0$.

It is possible that the linear relationships of Eq. 12 and 13 may be the initial portions of some exponential-type curves which may level-off to finite, asymptotic values of $\mathrm{Y}$ as $\mathrm{N}$ tends to infinity.

\section{Conclusions}

The Atterberg (Plastic and Liquid) Limits of these soils seem to be governed almost entirely by the clay contents with organic matter having little or no effect. The soils 
age-harden significantly when moist and care must be taken not to compare directly the strengths of aggregates which have been stored moist for different periods of time since moulding.

Tensile strength of the dry, remoulded aggregates is positively correlated with clay content and negatively correlated with porosity. These correlations for remoulded aggregates (Eq. 3) are very similar to those obtained for undisturbed, natural aggregates as shown by Eq. 6 in Part I (Dexter, Kroesbergen \& Kuipers, $1984)$. For the light soils $(2,3,8)$ the remoulded aggregates were made at a moisture content close to (No 3), at (No 2) or above (No 8) the liquid limit of the soil. That resulted in lower pore spaces than existed in the natural aggregates. For the other soils the moisture content at moulding was clearly below the liquid limit and for all those soils the pore space of the remoulded aggregates was higher than of the natural aggregates. A direct comparison between $Y$ for natural and $Y$ for remoulded aggregates is complicated by the difference in shape (Dexter \& Kroesbergen 1985). In Fig. 6 the relation between the increase or decrease in pore space at moulding is plotted to the strength ratio between remoulded and natural dry aggregates. The close relation indicates that pore space has a very important influence on $Y$. This regression is described by

$$
\frac{Y_{\text {rem }}}{Y_{\text {nat }}}=f \underbrace{}_{( \pm 1.07)}\left[\begin{array}{ll}
7.77 & \frac{\eta_{\text {rem }}}{\eta_{\text {nat }}}-6.85
\end{array}\right]
$$

where $f$ is an unknown factor which allows for the difference in shape between the remoulded and natural aggregates.

Eq. 4 predicts for the hypothetical case that aggregate tensile strength, $Y$, would be zero when porosity $\eta=0.463$. Similarly, Eq. 6 here predicts $Y=0$ for $\eta=0.442$. These values are close to that from Eq. 4 in Part I which predicts $Y=0$ for $\eta=$ 0.473 for undisturbed, natural aggregates of the light soils.

The friabilities of the dry, remoulded aggregates are about 0.4 of those of the natural aggregates. This is a reflection of the fact that the remoulded aggregates do not contain as many internal flaws such as micro-cracks or holes. The aggregates made from the puddled soil exhibited zero friability which indicates total homogeneity of the material on size scales of similar orders of magnitude as the aggregates.

The results of the studies of wetting and drying rates are summarized concisely in Eq. 8 and 9. This empirical approach is rather different from the more usual theoretical approach where wetting, for example, is simulated by using soil unsaturated hydraulic conductivity-water content curves together with soil water potential-water content curves.

The mellowing (or softening) of aggregates produced by wetting is an interesting and important phenomenon. The terms mellowing ratio, critical mellowing potential and critical slaking potential, which have been defined in this paper, will facilitate discussion of this phenomenon. The fact that mellowing can be anisotropic and the consequences that this could have in soil structure formation have been discussed elsewhere (Dexter, 1983). 


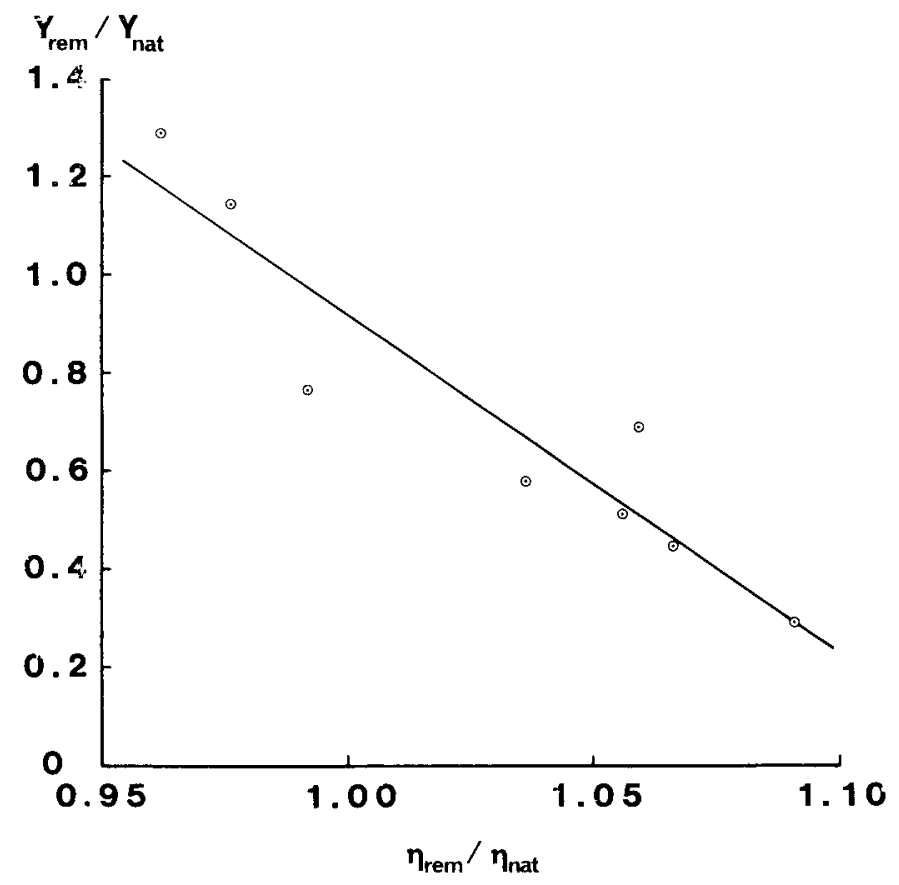

Fig. 6. Relation between the increase or decrease in pore space at moulding, expressed as $\eta_{\mathrm{rem}} / \eta_{\mathrm{nat}}$ and the strength ratio between remoulded and natural dry aggregates expressed as $Y_{\mathrm{rem}} / Y_{\text {nat }}$.

Progressive mellowing with increasing numbers of wetting and drying cycles has been illustrated in this paper. However, it is still not known how soil responds to very large numbers of wetting and drying cycles. It is possible that soil strength does not decrease to zero, but that a soil will attain an equilibrium strength and structural state depending on its composition and its environment. Slower wetting and drying than investigated here may result in increased densities as observed by Kuipers (1982) and therefore in stronger aggregates.

Further work needs to be done to investigate effects of soil conditions, such as initial water content, on aggregate mellowing. Also, it would be of considerable practical and theoretical interest to develop criteria to enable the effects of wetting and drying cycles in the laboratory to be related to the effects of wetting and drying cycles in the field. Wetting and drying is probably the most important factor in the restoration of structurally damaged soils, and yet an adequate scientific understanding of the phenomena involved is still a long way off.

\section{Acknowledgement}

A.R.D. wishes to thank the Agricultural University, Wageningen, for the award of a Senior Research Fellowship. 


\section{References}

Bouma, J., 1969. Micro-structure and stability of two sandy loam soils with different soil managements. Agricultural Research Report 724. Pudoc, Wageningen, $110 \mathrm{pp}$.

Dexter, A. R., 1983. Two types of soil anisotropy induced by the passage of a wetting front. Soil Science Society of America Journal 47: 1060-1061.

Dexter, A. R. \& B. Kroesbergen, in press. Methodology for determination of tensile strength of soil aggregates. Journal of Agricultural Engineering Research.

Dexter, A. R., B. Kroesbergen \& H. Kuipers, 1984. Some mechanical properties of aggregates of top soils from the IJsselmeerpolders. 1. Undisturbed soil aggregates. Netherlands Journal of Agricultural Science 32 (1984) 205-214.

Koolen, A. J.\& H. Kuipers, 1983. Agricultural soil mechanics. Springer-Verlag, Heidelberg, 241 pp.

Kuipers, H. 1982. Processes in soil physical degradation in mechanized agriculture. In: (D. Boels, D. B. Davies \& A. E. Johnston (Eds.), Soil degradation. Balkema, Rotterdam, 286 pp.

McIntyre, D. S. \& G. B. Stirk, 1954. A method for determination of apparent density of soil aggregates. Australian Journal of Agricultural Research 5: 291-296.

Utomo, W. H. \& A. R. Dexter, 1981a. Tilth mellowing. Journal of Soil Science 32: 187-201.

Utomo, W. H. \& A. R. Dexter, 1981b. Age hardening of agricultural top soils. Journal of Soil Science 32: $335-350$.

Utomo, W. H. \& A. R. Dexter, 1981c. Soil friability. Journal of Soil Science 32: 203-213. 